ORIGINAL ARTICLE

\title{
Lateralisation of language function in young adults born very preterm
}

\author{
T M Rushe, C M Temple, L Rifkin, P W R Woodruff, E T Bullmore, A L Stewart, A Simmons, \\ T A Russell, R M Murray
}

Arch Dis Child Fetal Neonatal Ed 2004;89:F112-F118. doi: 10.1136/adc.2001.005314

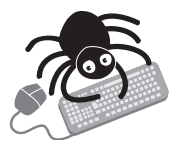

Full details of functional magnetic resonance imaging methodology are available at www. archdischild.com/ supplemental.

See end of article for authors' affiliations ....................

Correspondence to: Dr Rushe, Department of Psychology, University of Ulster at Jordanstown, $\mathrm{N}$ Ireland BT37 OQB: tm.rushe@ulst.ac.uk

Accepted

17 February 2003

\begin{abstract}
Objective: To explore, using functional magnetic resonance imaging (MRI), the functional organisation of phonological processing in young adults born very preterm.

Subjects: Six right handed male subjects with radiological evidence of thinning of the corpus callosum were selected from a cohort of very preterm subjects. Six normal right handed male volunteers acted as controls.

Method: Blood oxygenation level dependent contrast echoplanar images were acquired over five minutes at $1.5 \mathrm{~T}$ while subjects performed the tasks. During the $\mathrm{ON}$ condition, subjects were visually presented with pairs of non-words and asked to press a key when a pair of words rhymed (phonological processing). This task alternated with the OFF condition, which required subjects to make letter case judgments of visually presented pairs of consonant letter strings (orthographic processing). Generic brain activation maps were constructed from individual images by sinusoidal regression and non-parametric testing. Between group differences in the mean power of experimental response were identified on a voxel wise basis by analysis of variance.

Results: Compared with controls, the subjects with thinning of the corpus callosum showed significantly reduced power of response in the left hemisphere, including the peristriate cortex and the cerebellum, as well as in the right parietal association area. Significantly increased power of response was observed in the right precentral gyrus and the right supplementary motor area.

Conclusions: The data show evidence of increased frontal and decreased occipital activation in male subjects with neurodevelopmental thinning of the corpus callosum, which may be due to the operation of developmental compensatory mechanisms.
\end{abstract}

$\mathrm{P}$ revious studies documenting language function in low birthweight and very low birthweight children have reported phonological and articulatory problems ${ }^{12}$ in the period between infancy and preschool. Findings from older preterm children have been inconclusive. For example, at school age, 5 year olds are reported to have normal language development, ${ }^{3}$ but other studies have reported delays in expressive language and sentence repetition at ages 6 and 7 years. ${ }^{45}$ Language deficits in articulation, quality of speech, and naming of numbers were the only deficits to remain in six year olds born very preterm, after controlling for general cognitive ability. ${ }^{5}$ Similarly, we reported previously that a deficit in language production (verbal fluency) was evident in very preterm survivors at age $14-15$, although their reading and spelling performance was comparable to that of the controls. ${ }^{6}$

The present study used functional magnetic resonance imaging (MRI) to study the impact of neurodevelopmental damage to the corpus callosum on phonological processing in young adults who had been born very preterm. A recent structural MRI study reported that $55 \%$ of a cohort of 75 infants born at less than 33 weeks gestation had evidence of brain abnormality in adolescence. The most common abnormality was ventricular enlargement followed by thinning/atrophy of the corpus callosum. ${ }^{7}$

We chose to study phonological processing in this study for two reasons. Firstly, the importance of phonological processing in the acquisition of reading and spelling skills is well documented, ${ }^{8}$ and early impairments in such are likely to contribute to the need for extra educational provision associated with very preterm survivors at school age. ${ }^{79}$
Secondly, phonological processing has been shown previously to be preferentially disrupted by developmental damage to the corpus callosum. ${ }^{10-12}$ Temple et al showed a specific impairment in phonological processing in children with callosal agenesis, which they attributed to failure of complete lateralisation of language function in this group. Reduced cerebral asymmetry, and the failure to lateralise language function to the left hemisphere, has also been posited as an important determinant of reading disability in children with developmental dyslexia. ${ }^{5}$

We hypothesised that young adults born very preterm and with evidence of callosal thinning would display incomplete lateralisation of language function to the left hemisphere. Instead they would show evidence of bilateral activation when performing phonological processing tasks, which previously have been shown to be preferentially disrupted by developmental abnormality of the corpus callosum.

\section{METHODS \\ Subjects}

Six right handed men with evidence of corpus callosal thinning on structural MRI at age 14 were identified from a larger cohort of adolescents born very preterm. ${ }^{7}$ The very preterm subjects were treated at the neonatal unit of University College Hospital, London during the years 1979 and 1980, and have been involved in follow up assessments

Abbreviations: MRI, magnetic resonance imaging; VWF, visual word form 
at $1,4,8$, and 14 years of age. At age 14-15, 75 subjects participated in a structural MRI study ${ }^{7}$ and were recruited to this study on the basis of their MRI status at that time. The MR images were rated independently by two consultant neuroradiologists who were blind to subject status. In two subjects, the corpus callosal thinning extended from the genu to the splenium, and in two subjects the thinning was observed in the anterior and posterior body. In the remaining three subjects the thinning was observed in the posterior body only (fig 1). In addition, all very preterm subjects had evidence of ventricular enlargement.

Table 1 gives the background characteristics of the very preterm and control subjects. Six age matched right handed men acted as controls, all of whom were born full term and with normal delivery. None had evidence of callosal thinning and all were free from any neurological or psychiatric illness. Subjects gave written informed consent before the scan.

\section{Ethics}

Ethical permission for the study was obtained from the Institute of Psychiatry and Maudsley NHS Trust research ethics committee.

\section{Activation tasks}

The activation paradigm consisted of an alternating ON-OFF (target task-control task) design. For the target activation task (presented during the ON phase) subjects were required to make rhyme judgments about pairs of non-words. During the OFF phase, a letter case judgment task was presentedthat is, two sets of consonant strings were displayed and subjects decided whether they contained the same pattern of case alternation. Stimulus pairs were presented visually on the computer screen in 10 alternating (non-words versus letter case) phases, each phase being a block of six stimulus pairs corresponding to that phase ( 30 seconds per block). The stimuli were presented from a PC via a video projector and a mirror system into the MR scanner. Subjects made a samedifferent judgment, pressing a button box with the index finger of the right hand if the pair was the same. After five seconds, the next stimulus pair was presented. For each task, target stimuli were presented randomly, with a frequency of two per phase. The rate of presentation, decision (same versus different), motor response component (pressing a button), and frequency of target responses for each task were the same. Accuracy of response was recorded for each

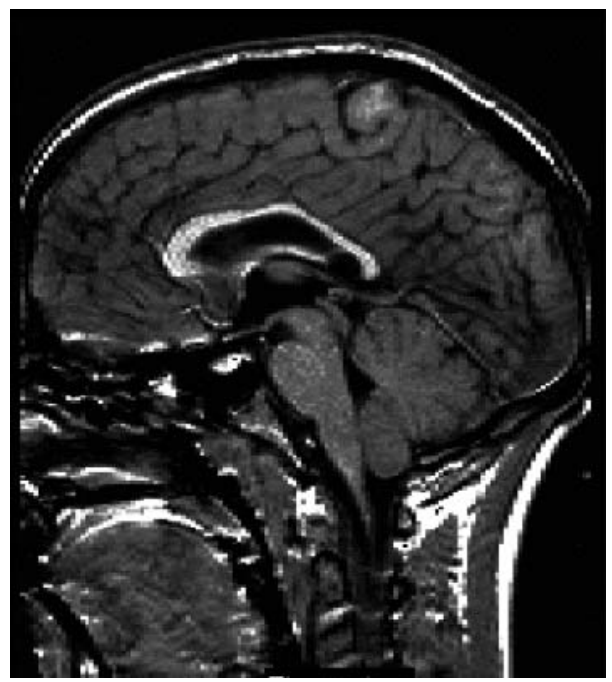

Figure 1 Image from a very preterm subject showing evidence of thinning of the corpus callosum.
Table 1 Basic characteristics of the subjects in the study

\begin{tabular}{lll}
\hline & Very preterm $(\mathbf{n = 6})$ & Controls $(\mathbf{n = 6 )}$ \\
\hline Age (years) & $18.17(1.29)$ & $18.83(1.47)$ \\
Gestation (weeks) & $28.83(2.64)$ & Full term \\
Birth weight (g) & $1360(237)$ & $>2500$ \\
\hline Values are mean (SD). &
\end{tabular}

subject. All subjects were trained on the tasks before being scanned, and performance was recorded during scanning.

\section{Image acquisition}

Gradient echo echoplanar MR images were acquired using a 1.5 T GE Signa System retrofitted with Advanced NMR hardware. For the five minute experiment, $100 \mathrm{~T} 2 *$ weighted MR images depicting blood oxygenation level dependent contrast ${ }^{13}$ were acquired at each of 14 non-contiguous, near axial planes parallel to the intercommissural (anterior commissural-posterior commissural) line ( $\mathrm{TE}=40$ milliseconds; $\mathrm{TR}=3000$ milliseconds; in plane resolution $=3.1 \mathrm{~mm}$; slice thickness $=7.7 \mathrm{~mm}$; slice skip $=0.7 \mathrm{~mm}$ ) To facilitate later registration of individual functional MRI data sets in standard space, a 43 slice, high resolution inversion recovery echoplanar image of the whole brain was acquired in the anterior commissural-posterior commissural plane $(\mathrm{TE}=73$ milliseconds; $\mathrm{TI}=180$ milliseconds; $\mathrm{TR}=16000$ milliseconds; in plane resolution $=1.5 \mathrm{~mm}$; slice thickness $=3 \mathrm{~mm}$ ).

\section{Image analysis}

The statistical inference software package Brain Activation and Morphological Mapping (XBAMM; Brain Imaging Analysis Unit, Institute of Psychiatry) was used to analyse functional MR images. A periodic time course procedure was adopted, which is described fully by Bullmore et al. ${ }^{14}$ By keeping the task parameters constant throughout each experimental condition, it was possible to fit a sinusoidal waveform to the frequency of presentation of the contrasting stimuli in each phase, thus revealing brain activity that distinguished the ON and OFF phases. In addition, the procedure adopted made it possible to determine the polarity of activity in relation to input, permitting the examination of regions showing greater responses to the $\mathrm{ON}$ phase and those that showed greater responses during the OFF phase. Yellow voxels are activated with maximum intensity during the nonword rhyme task, and blue voxels are activated with maximum intensity during the letter case judgment task.

\section{RESULTS}

\section{On line task performance}

Out of a possible maximum score of 10 errors for each condition, the median number of errors for the control group was 0 (range $0-1$ ) for both the non-word rhyming and case alternation tasks. For the very preterm group, the median score was 0.5 for both tasks, with a range of $0-5$ for the nonword rhyming task, and a range of $0-2$ for the case alternation task. These group differences were not significant (non-word rhyming task Mann-Whitney U test, $11 ; \mathrm{p}>0.1$; case alternation task Mann-Whitney U test, 14; p >0.1).

\section{Brain activation in phase with non-word rhyming}

Figure 2 and table 2 show activation in phase with non-word rhyming for the control group. Controls showed significantly increased activation bilaterally in the peristriate cortex, precuneus, superior frontal cortex (the pre and supplementary motor area), and the insula. Left sided activation was observed in the inferior frontal gyrus (Broca's area), the 
A
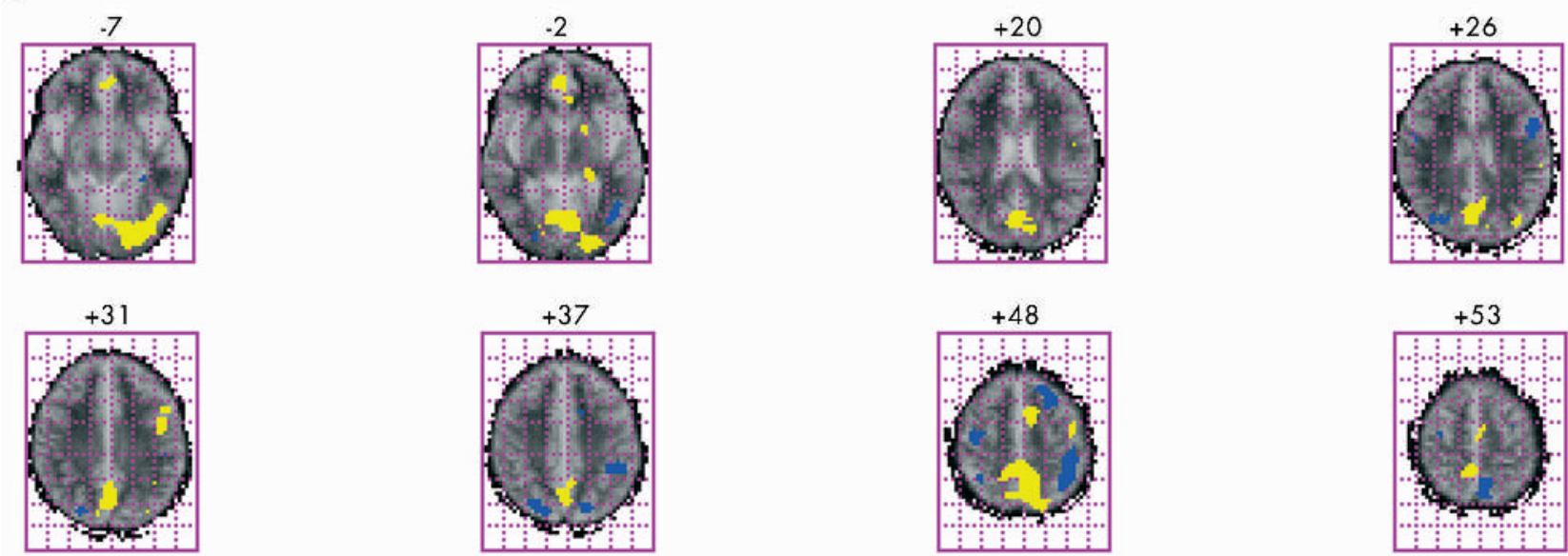

B

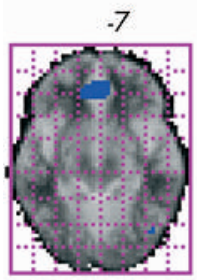

$+31$

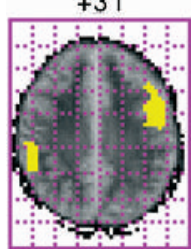

$-2$

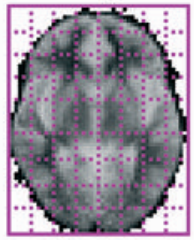

$+37$

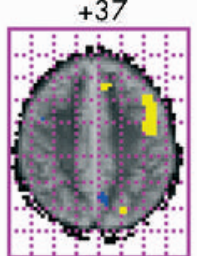

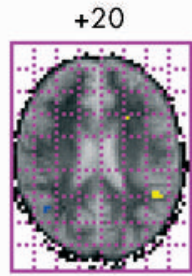

$+48$

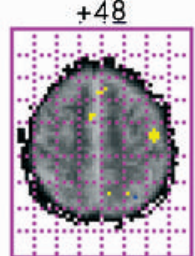

$+53$

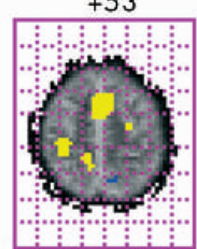

Figure 2 Brain activation in phase with non-word rhyming (shown in yellow) and case alternation judgment (shown in blue) of six controls (A) and six very preterm subjects with thinning of the corpus callosum (B). For each brain image, the left hemisphere is represented on the right of the image, and the right hemisphere is represented on the left.

precentral gyrus, the middle temporal gyrus, the retrosplenial cortex, and the putamen. Activation restricted to the right hemisphere was seen in the medial frontal lobe, the superior temporal gyrus, and the cingulate and post cingulate gyri.

Inspection by eye of the power of response to the non-word rhyming tasks (shown in yellow) suggests that the very preterm group showed reduced activation inferiorly and posteriorly relative to the control group (fig 2 and table 3 ). Between group differences in the mean power of experimental were identified on a voxel wise basis by analysis of covariance procedures, which control for the possible confounding effect of a between group difference in stimulus correlated motion. ${ }^{14}$ The data are presented in table 4 and the corresponding images in fig 3. Compared with the control group, the very preterm group showed significantly reduced power of response in the left peristriate cortex, the left cerebellum, and the right precuneus. Significantly increased activation for the very preterm group compared with controls was observed in the right hemisphere, the precentral gyrus, and superior frontal cortex.

Compared with the very preterm group, the control group showed significantly more power of response in the left precuneus and the left peristriate cortex during execution of the letter case judgment task (table 4).

\section{DISCUSSION}

We examined the functional neuroanatomy of phonological processing in a group of young adults born very preterm and with evidence of thinning of the corpus callosum and hypothesised that, compared with controls, the preterm subjects with callosal thinning would exhibit a pattern of bilateral activation. Compared with controls, the preterm subjects had reduced activation in the left peristriate cortex, the left cerebellum, and the right precuneus. Significantly more activation was found in the precentral gyrus and the superior frontal gyrus in the right hemisphere.

The results of the control group in response to non-word rhyming are broadly consistent with previous studies that have explored phonological processing in normal subjects using positron emission tomography ${ }^{15-18}$ and functional MRI ${ }^{19}{ }^{20}$ in that activation was evident in the left perisylvian structures including Broca's area and the area adjacent, the superior frontal cortex. Additional foci were observed in the left middle temporal gyrus, the left precentral gyrus, the left retrosplenial cortex, and the putamen. Activation was observed bilaterally in the precuneus, the peristriate cortex, and the insula, and right hemisphere activation included the cingulate and posterior cingulate gyrus. Thus, even in normal right handed male subjects, processing of visual linguistic stimuli is not limited to the left hemisphere. 
Table 2 Main regional foci of brain activation, with periodic signal maximum during non-word rhyming in the control group

\begin{tabular}{|c|c|c|c|c|c|c|}
\hline & \multirow{2}{*}{$\begin{array}{l}\text { Number of } \\
\text { voxels }\end{array}$} & \multicolumn{3}{|c|}{ Talairach coordinates $(\mathrm{mm})$} & \multirow[b]{2}{*}{ Max FPQ } & \multirow{2}{*}{$\begin{array}{l}\text { Prob (max } \\
F P Q \text { ) }\end{array}$} \\
\hline & & $x$ & y & $z$ & & \\
\hline \multicolumn{7}{|l|}{ Left hemisphere } \\
\hline Precuneus & 103 & -6 & -50 & 48 & 2.0 & 0.000004 \\
\hline \multirow[t]{2}{*}{ Peristriate cortex } & 101 & -20 & -81 & -7 & 1.9 & 0.000004 \\
\hline & 8 & -29 & -83 & 4 & 1.5 & 0.000423 \\
\hline \multirow[t]{2}{*}{ Parastriate cortex } & 31 & -40 & -64 & -13 & 1.7 & 0.000022 \\
\hline & 8 & -32 & -69 & 26 & 1.6 & 0.000288 \\
\hline Superior frontal gyrus & 26 & -6 & 8 & 48 & 1.7 & 0.000026 \\
\hline \multirow{2}{*}{ Precentral gyrus } & 23 & -40 & -6 & 48 & 1.6 & 0.000052 \\
\hline & 14 & -40 & -3 & 31 & 1.6 & 0.00007 \\
\hline Retrosplenial cortex & 10 & -20 & -31 & -2 & 1.6 & 0.000052 \\
\hline Inferior frontal gyrus & 6 & -43 & 8 & 31 & 1.6 & 0.000353 \\
\hline Insula & 5 & -46 & 3 & -2 & 1.6 & 0.000362 \\
\hline Putamen & 5 & -14 & 3 & -2 & 1.6 & 0.000240 \\
\hline \multicolumn{7}{|l|}{ Right hemisphere } \\
\hline Post cingulate gyrus & 34 & 3 & -67 & 20 & 1.7 & 0.000004 \\
\hline \multirow{2}{*}{$\begin{array}{l}\text { Precuneus } \\
\text { Pros }\end{array}$} & 33 & 3 & -58 & 31 & 1.7 & 0.000013 \\
\hline & 23 & 3 & -56 & 37 & 1.6 & 0.000057 \\
\hline \multirow[t]{3}{*}{ Peristriate cortex } & 86 & 0 & -67 & 9 & 1.9 & 0.000004 \\
\hline & 32 & 3 & -61 & 26 & 1.8 & 0.000004 \\
\hline & 23 & 12 & -47 & 4 & 2.0 & 0.000004 \\
\hline Medial frontal lobe & 18 & 6 & 42 & -2 & 1.6 & 0.000288 \\
\hline Insula & 12 & 40 & 19 & 9 & 1.6 & 0.000074 \\
\hline Ant-mid cingulate gyrus & 7 & 9 & -11 & 42 & 1.6 & 0.000126 \\
\hline Superior frontal gyrus & 6 & 3 & -11 & 59 & 1.6 & 0.000179 \\
\hline Superior temporal gyrus & 6 & 49 & -31 & 9 & 1.6 & 0.000392 \\
\hline \multicolumn{7}{|c|}{$\begin{array}{l}x, y \text {, and } z \text { refer to the stereotactic coordinates }{ }^{36} \text { of the voxel within each cluster with the largest fundamental power } \\
\text { quotient (FPQ, reflecting the significance of periodic change), and Prob (max FPQ) indicates the probability of false } \\
\text { activation. The reference point for the coordinates is the junction of the vertical anterior commissural line and the } \\
\text { intercommissural line. The reference plane is the bicommissural plane. } x \text { refers to millimetres left (-) and right of the } \\
\text { reference point, } y \text { to millimetres anterior and posterior (-) to the reference point, and } z \text { to planes above and below } \\
(-) \text { the reference plane. }\end{array}$} \\
\hline
\end{tabular}

Peristriate activation by the control group is notable, as the very preterm group showed significantly reduced power of activation during both the rhyme judgment and case alternation tasks in the peristriate cortex. Activation in the peristriate cortex is consistent with some previous studies that explored normal brain activity associated with the visual presentation of words, and there is converging evidence that this region is active in the early orthographic processing of linguistic stimuli. ${ }^{21-23}$ Petersen et a ${ }^{21}$ labelled this region the visual word form (VWF) system, which corresponds to the

Table 3 Main regional foci of brain activation, with periodic signal maximum during non-word rhyming in the preterm group

\begin{tabular}{|c|c|c|c|c|c|c|}
\hline & \multirow{2}{*}{$\begin{array}{l}\text { Number of } \\
\text { voxels }\end{array}$} & \multicolumn{3}{|c|}{ Talairach coordinates (mm) } & \multirow{2}{*}{\multicolumn{2}{|c|}{$\begin{array}{l}\text { Prob (max } \\
\text { Max FPQ FPQ) }\end{array}$}} \\
\hline & & $\mathbf{x}$ & $y$ & $\mathbf{z}$ & & \\
\hline \multicolumn{7}{|l|}{ Left hemisphere } \\
\hline Post central gyrus & 7 & -32 & -44 & 42 & 1.6 & 0.0004 \\
\hline Superior temporal gyrus & 27 & -49 & -39 & 15 & 1.6 & 0.00006 \\
\hline Inf post temporal lobe & 7 & -43 & -61 & 9 & 1.6 & 0.0001 \\
\hline \multirow[t]{4}{*}{ Superior frontal gyrus } & 51 & -46 & 3 & 31 & 1.9 & 0.000004 \\
\hline & 37 & -40 & 0 & 37 & 1.8 & 0.000004 \\
\hline & 34 & -49 & 0 & 26 & 1.8 & 0.000004 \\
\hline & 17 & -40 & -8 & 42 & 1.6 & 0.00003 \\
\hline Dorsolateral prefrontal cortex & 12 & -6 & 31 & 42 & 1.7 & 0.000004 \\
\hline Precentral gyrus & 8 & -40 & -8 & 48 & 1.6 & 0.00003 \\
\hline Auditory association cortex & 5 & -43 & -44 & 20 & 1.6 & 0.000062 \\
\hline Medial frontal lobe & 5 & -6 & 28 & 37 & 1.7 & 0.000036 \\
\hline \multicolumn{7}{|l|}{ Right hemisphere } \\
\hline \multirow[t]{2}{*}{ Supramarginal gyrus } & 24 & 55 & -25 & 31 & 1.7 & 0.000004 \\
\hline & 34 & 55 & -22 & 26 & 1.7 & 0.000004 \\
\hline Superior temporal gyrus & 16 & 46 & -28 & 4 & 1.7 & 0.00004 \\
\hline \multirow[t]{2}{*}{ Superior frontal gyrus } & 38 & 0 & 6 & 53 & 1.8 & 0.00004 \\
\hline & 38 & 0 & -3 & 59 & 1.8 & 0.00004 \\
\hline \multirow[t]{3}{*}{ Precentral gyrus } & 17 & 32 & -28 & 53 & 1.7 & 0.00004 \\
\hline & 14 & 29 & -22 & 59 & 1.7 & 0.00001 \\
\hline & 10 & 14 & -33 & 53 & 1.6 & 0.00002 \\
\hline Insula & 17 & 43 & 6 & 9 & 1.7 & 0.00004 \\
\hline \multicolumn{7}{|c|}{$\begin{array}{l}x, y, \text { and } z \text { refer to the stereotactic coordinates }{ }^{36} \text { of the voxel within each cluster with the largest fundamental pow } \\
\text { quotient (FPQ, reflecting the significance of periodic change), and Prob (max FPQ) indicates the probability of fal } \\
\text { activation. The reference point for the coordinates is the junction of the vertical anterior commissural line and th } \\
\text { intercommissural line. The reference plane is the bicommissural plane. } x \text { refers to millimetres left }(- \text { ) and right of th } \\
\text { reference point, } y \text { to millimetres anterior and posterior }(-) \text { to the reference point, and } z \text { to planes above and belo } \\
(-) \text { the reference plane. }\end{array}$} \\
\hline
\end{tabular}


Table 4 Cerebral regions showing significantly different power of response to the nonword rhyming task and the letter case judgment task between the very preterm group and the control group

\begin{tabular}{|c|c|c|c|c|c|}
\hline & \multirow{2}{*}{$\begin{array}{l}\text { Number of } \\
\text { voxels }\end{array}$} & \multicolumn{3}{|c|}{ Talairach coordinates (mm) } & \multirow{2}{*}{$\begin{array}{l}\text { Maximum difference } \\
\text { in } \mathrm{FPQ}\end{array}$} \\
\hline & & $\mathbf{x}$ & $y$ & $\mathbf{z}$ & \\
\hline \multicolumn{6}{|l|}{ Non-word rhyming } \\
\hline \multicolumn{6}{|l|}{ Controls $>$ very preterm group } \\
\hline Left peristriate cortex & 13 & -3 & -64 & -2 & 0.3 \\
\hline Right precuneus & 8 & 3 & -56 & 48 & 0.3 \\
\hline Left cerebellum & 6 & -38 & -64 & -13 & 0.3 \\
\hline \multicolumn{6}{|l|}{ Very preterm group $>$ controls } \\
\hline Right precentral gyrus & 7 & 26 & -22 & 59 & 0.3 \\
\hline Right superior frontal gyrus & 6 & 3 & 3 & 59 & 0.3 \\
\hline \multicolumn{6}{|l|}{ Letter case judgment } \\
\hline \multicolumn{6}{|l|}{ Controls > very preterm group } \\
\hline \multirow[t]{2}{*}{ Left peristriate cortex } & 6 & -14 & -53 & 4 & 0.3 \\
\hline & 5 & -26 & -86 & -2 & 0.3 \\
\hline Left precuneus & 9 & -20 & -61 & 42 & 0.3 \\
\hline $\begin{array}{l}x, y \text {, and } z \text { refer to the stereotac } \\
\text { quotient }(F P Q \text {, reflecting the sig } \\
\text { of the vertical anterior commiss } \\
\text { plane. } x \text { refers to millimetres lef } \\
\text { the reference point, and } z \text { to } p\end{array}$ & $\begin{array}{l}\text { ordinates }{ }^{36} \text { of } \\
\text { nce of periodi } \\
\text { ine and the in } \\
\text { and right of th } \\
\text { above and be }\end{array}$ & ercomm & $\begin{array}{l}\text { in eac } \\
\text { e refer } \\
\text { ral line } \\
\text { soint, y } \\
\text { referen }\end{array}$ & $\begin{array}{l}\text { with } t \\
\text { oint for } \\
\text { eferenc } \\
\text { imetres }\end{array}$ & $\begin{array}{l}\text { est fundamental power } \\
\text { ordinates is the junction } \\
e \text { is the bicommissural } \\
\text { or and posterior }(-) \text { to }\end{array}$ \\
\hline
\end{tabular}

visual input lexicon in dual route theories of reading. ${ }^{24}$ Orthographic to phonological representation occurs more readily for words recognised as legitimate word forms by the visual input lexicon. Reduced activation in this area by the preterm subjects may occur as a result of an inefficient VWF system and the adoption of a more effortful phonological approach to the task in order to carry it out and keep performance in line with controls.

Research by Cohen et al ${ }^{25}$ suggests that abnormalities of the corpus callosum may impact on the function of the VWF system. Posterior split brain patients failed to activate the left inferior temporal lobe area (their VWF system) when words were presented to their left visual field. These words were disadvantaged because they are processed initially in the right hemisphere and require transfer via the corpus callosum to the left hemisphere for linguistic processing. In contrast with our subjects, their two subjects sustained damage to the posterior part of the corpus callosum in adulthood, presumably after a period of normal brain development. For the subjects in our study, however, the corpus callosum damage was sustained very early in development, which may have resulted in the failure of the VWF system to develop properly as an important module in the functional architecture of reading. An alternative strategy for the reading of words may have been the adoption of a more effortful phonological approach to the task in order to conduct the task and keep performance in line with controls. This is consistent with the finding that our subjects displayed a pattern of hyperfrontality. Cohen et $a^{25}$ also reported that precentral and prefrontal activation in the left hemisphere was unique to their split brain patients and associated only with words presented in the left visual field, which, as stated above, did not have access to the VWF system. They interpreted this unexpected finding as a possible reflection of the slow and effortful search for a verbal response. However, as the responses were not timed in this study, the hypothesis that this activation is related to slower and more effortful performance is tentative.

The results from the very preterm group suggest a pattern of hyperfrontality in the right hemisphere and hypooccipitality in the left hemisphere. It is not clear, however, if this pattern of activation is specific to phonological processing, as reduced parietal and occipital responses in the left hemisphere were also observed during execution of

\section{$-13$}

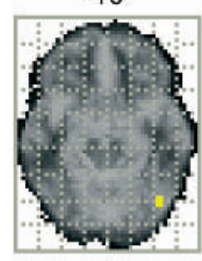

$+42$

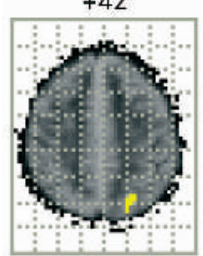

$-2$

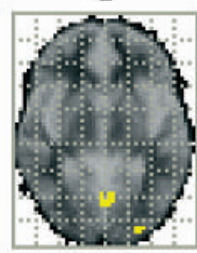

$+48$

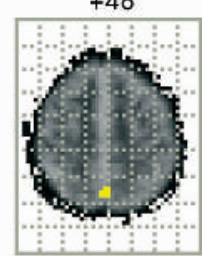

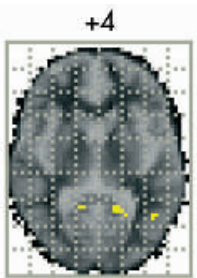

$+59$

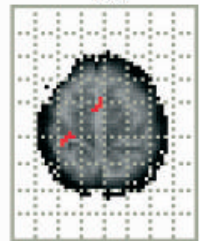

Figure 3 Brain activation pattern showing the regional differences between the two groups (six very preterm subjects and six controls) after analysis of covariance. Regions shown in yellow are those that show significantly more activation in the control group. Regions shown in red are those that show significantly more activation for the very preterm subjects with evidence of thinning of the corpus callosum. 
the letter case judgment task in this group. Our results also show that large regions of activation unique to the control task were evident in the left inferior frontal and superior temporal regions, suggesting that the task assumed some linguistic properties (fig 2).

Other group differences that were not predicted include significantly less activation in the cerebellum and the right precuneus during the rhyme judgment task and reduced activation in the left precuneus during the case alternation task. The cerebellum and the precuneus or the parietal association area showed increased activation in a number of studies of phonological processing, yet the precise contribution of these areas to the network of phonological processing remains to be established.

We cannot confirm whether the corpus callosum is important during development for hemispheric specialisation for language. Preterm infants are prone to develop cerebral injury in the perinatal period, mainly as a result of cerebral haemorrhage and hypoxic-ischaemic damage. ${ }^{26}$ Ventricular enlargement and white matter abnormalities including thinning of the corpus callosum ensue. Although none of our subjects had evidence of cortical atrophy when their scans were rated qualitatively, other studies using quantitative MRI methods in this group have shown that perinatal brain damage is associated with atrophy of the parietooccipito cortex, ${ }^{27-29}$ the cerebellum, and the hippocampus. ${ }^{30} 31$ Even minor degrees of hypoxic-ischaemic damage to the cortex sustained in the prenatal and perinatal period can affect callosal fibres that lie very close to the typical site for periventricular leucomalacia. ${ }^{32}$ Alternatively, nutritional influences in the neonatal period may have been involved, as the period between birth and term is one of relative malnutrition for many very preterm infants because of acute and chronic illness and poor feed tolerance. ${ }^{33}$ This may have adversely affected myelination of the corpus callosum, which does not begin until after term. ${ }^{26} \mathrm{~A}$ diet of nutrient enriched formula in the early weeks post partum was found to have a major impact on later growth and development of very preterm infants. $^{34}$ Thus, whether or not our finding of alternative functional activation in very preterm survivors is due to the effects of hypoxic-ischaemic damage or to reduced myelination of the callosal fibres in the neonatal period remains to be established.

The small sample size and restriction of the sample to male subjects in this study limits the comparability of these findings to other very preterm subjects with damage to the corpus callosum. Also, at age $14-15$, the very preterm sample from which the present sample was drawn displayed a specific deficit in verbal fluency. ${ }^{6}$ However, in the present study, phonological processing, as measured by the non-word rhyming task, and orthographic processing, as measured by the case alternation task, was comparable to that of the controls. Thus, whether or not those very preterm survivors with persistent language deficits show a similar pattern of activation to those without remains to be established.

We reported previously that qualitative ratings of white matter abnormalities and ventricular enlargement were not related to any measure of neuropsychological function. ${ }^{6}$ We hypothesised that the lack of relation between brain pathology and cognitive function may be explained by developmental compensatory mechanisms such as neural and/or functional plasticity. The ability to compensate with alternative neural networks, such as hyperfrontal activation in the right hemisphere, may contribute to successful performance on the phonological processing task, despite neurodevelopmental callosal abnormality. We also recognise the importance of environmental factors in mediating cognitive outcome in very preterm survivors. A recent study showed that family factors were stronger predictors of school performance than were perinatal complications. ${ }^{9}$ Also, given that recent studies from neuroscience have shown that experience and function can alter and determine brain structure, ${ }^{35}$ we support the more plastic concept of functional and neural compensation in the mediation of cognitive difficulties in this group

This study using functional MRI has shown that such neurodevelopmental damage results in altered structurefunction relations in later life. Although our findings are consistent with the hypothesis that very preterm subjects display a pattern of bilateral activation in response to phonological processing tasks, it remains to be established if this is specific to such processing and/or is specifically a consequence of corpus callosum abnormality in this group.

\section{Authors' affiliations}

T M Rushe, Department of Psychology, University of Ulster at Jordanstown, N Ireland BT37 OQB

C M Temple, Department of Psychology, University of Essex, Colchester, Essex, UK

L Rifkin, T A Russell, R M Murray, Department of Psychiatry, Institute of Psychiatry, King's College, London, UK

P W R Woodruff, Department of Psychiatry, University of Sheffield, Sheffield, UK

E T Bullmore, Department of Psychiatry, University of Cambridge, Cambridge, UK

A L Stewart, Perintal Brain Research Group, Department of Paediatrics, University College London Medical School, London, UK

A Simmons, Department of Neurology, Institute of Psychiatry, King's College, London, UK

\section{REFERENCES}

1 Byers-Brown B, Bendersky M, Chapman T. The early utterances of preterm infants. Br J Disord Commun 1986;21:307-19.

2 Briscoe J, Gathercole SE, Marlow N. Short-term memory and language outcomes after extreme prematurity at birth. Journal of Speech Language and Hearing Research 1998;41:654-66.

3 Rickards AL, Ford GW, Kitchen WH, et al. Extremely-low-birthweight infants: neurological, psychological, growth and health status beyond five years of age. Med J Aust 1987; 147:476-81.

4 Largo RH, Molinari L, Comenale Pinto L, et al. Language development of term and preterm children during the first five years of life. Dev Med Child Nevorol 1986;28:333-50

5 Wolke D, Meyer R. Cognitive status, language attainment, and pre reading skills of 6-year-old children and their peers: the Bavarian longitudinal study. Dev Med Child Neurol 1999;41:94-109.

6 Rushe T, Rifkin L, Stewart A, et al. Neuropsychological outcome of very preterm birth and its relationship to brain structure. Dev Med Child Neurol 2001;43:226-33.

7 Stewart AL, Rifkin L, Amess PN, et al. Brain structure and neurocognitive and behavioural function in adolescents who were born very preterm. Lancet 1999;353:1653-7.

8 McBride-Chang C, Kail RV. Cross-cultural similarities in the predictors of reading acquisition. Child Development 2002;73:1392-407.

9 Gross SJ, Metteleman BB, Dye TD, et al. Impact of family structure and stability on academic outcome in preterm children at 10 years of age. $J$ Pediatr 2001;138:169-75.

10 Temple CM, Jeeves MA, Vilarroya OO. Ten pen men: explicit phonological processing in two children with callosal agenesis. Brain and Language 1997;37:548-64.

11 Temple CM, Jeeves MA, Vilarroya OO. Reading in callosal agenesis. Brain and Language 1990;39:235-53.

12 Temple CM, Ilsey J. Phonemic discrimination in callosal agenesis. Cortex 1993;29:341-8.

13 Ogawa S, Lee TM, Nayak AS, et al. Oxygenation sensitive contrast in magnetic resonance image of rodent brain at high magnetic fields. Magn Reson Med 1990;14:68-78.

14 Bullmore $E$, Brammer $M$, Williams $S$, et al. Statistical methods of estimation and inference of functional MR Image analysis. Magn Reson Med 1996;35:261-77.

15 Demonet JF, Chollet F, Ramsey S, et al. The anatomy of phonological and semantic processing in normal subjects. Brain 1992;115:1753-68.

16 Sergent J, Zuck E, Levesque $M$, et al. Positron emission tomography study of lefter and object processing: empirical findings and methodological considerations. Cerebral Cortex 1992;2:68-80.

17 Zatorre R, Evans A, Meywr E, et al. Lateralisation of phonetic and pitch discrimination in speech processing. Science 1992;256:846-9.

18 Paulesu E, Frith CD, Frackowick RSJ. The neural correlates of the verbal component of working memory. Nature 1993;362:342-5. 
19 Paulesu E, Connelly A, Frith CD et al. Functional MRI correlations with PET. Initial experience using a cognitive activation paradigm on verbal working memory. Neuroimaging Clinics of North America 1995;5:207-12.

20 Pugh KR, Shaywitz BA, Shaywitz SE, et al. Cerebral organisation of component processes in reading. Brain 1996;119:1221-38.

21 Petersen SE, Fox PT, Snyder AZ, et al. Activation of extrastriate and frontal cortical areas by visual words and word-like stimuli. Science 1990;249:1041-4

22 Chee MW, O'Craven KM, Bergida R, et al. Auditory and visual word processing studied with FMRI. Human Brain Mapping 1999;7:15-28.

23 Price CJ, Wise RJ, Warburton EA, et al. Hearing and saying. The functional neuro-anatomy of auditory word processing. Brain 1996;119:919-31.

24 Coltheart M, Curtis B, Atkins $P$, et al. Models of reading aloud: dual route and parallel-distributed-processing approaches. Psychol Rev 1993; 100:589-608

25 Cohen L, Dehaene S, Naccache L, et al. The visual word form area: spatial and temporal characterization of an initial stage of reading in normal subjects and posterior split-brain patients. Brain 2000;123:291-307.

26 Stewart A, Hope PL, Hamilton P, et al. Prediction in very preterm infants of satisfactory neurodevelopmental progress at 12 months. Dev Med Child Neurol 1988;30:53-63.

27 Petersen BS, Vohr B, Staib LH, et al. Regional brain abnormalities and cognitive outcome in preterm subjects. JAMA 2000;284:1939-47.

28 Eken $\mathrm{P}$, deVries LS, van der Graaf Y, et al. Haemorrhagic-ischaemic lesions of the neonatal brain: correlation between cerebral visual impairment, neurodevelopmental outcome and MRI in infancy. Dev Med Child Neurol 1995;37:41-55

29 Jacobson L, Ek U, Fernell E, et al. Visual impairment in preterm children with periventricular leukomalacia: visual, cognitive and neuropaediatric characteristics related to cerebral imaging. Dev Med Child Neurol 1996;38:724-35.

30 Allin M, Matsumoto H, Santhouse AM, et al. Cognitive and motor function and the size of the cerebellum in adolescents born very pre-term. Brain $2001 ; 124: 60-6$.

31 Nosarti C, Alsady MH, Frangou S, et al. Adolescents who were born very preterm have decreased brain volumes. Brain 2002;125:1616-23.

32 Moses P, Courchesne E, Stiles J, et al. Regional size reduction in the human corpus callosum following pre and perinatal brain injury. Cerebral Cortex 2000;10:1200-10.

33 Cooke RWI, Abernethy $\sqcup$. Cranial magnetic resonance imaging and school performance in very low birth weight infants in adolescence. Arch Dis Child Fetal Neonatal Ed 1999;81:F116-21.

34 Lucas A, Morley R, Cole TJ, et al. Early diet in preterm babies and developmental status at 18 months. Lancet 1990;335:1477-81.

35 Rubia K. The dynamic approach to neurodevelopmental psychiatric disorders: use of FMRI combined with neuropsychology to elucidate the dynamics of psychiatric disorders, exemplified in ADHD and schizophrenia. Behav Brain Res 2002;130:47-56

36 Talairach J, Tournoux P. Co-planar stereotaxic atlas of the human brain: 3dimensional proportional system: an approach to cerebral imaging. Stuttgart: $\mathrm{G}$ Thieme, 1988 